\title{
Magnitude of Coccidia Infection in Small Scale Broiler Chicken Farms of Rural Assam (India)
}

\author{
A. Kalita ${ }^{1 *}$, P.C. Sarmah ${ }^{1}$, M.K. Borah ${ }^{2}$, L. Hussain ${ }^{3}$ and K. Bhattacharjee ${ }^{1}$ \\ ${ }^{1}$ Department of Parasitology, ${ }^{2}$ Department of Poultry, ${ }^{3}$ Department of Extension, College of \\ Veterinary Science, Khanapara, Guwahati-781022, Assam, India \\ *Corresponding author
}

\begin{tabular}{|l|}
\hline Ke y w or d s \\
$\begin{array}{l}\text { Coccidia, Broiler } \\
\text { chicken, Assam, } \\
\text { India }\end{array}$ \\
\hline Article Info \\
\hline $\begin{array}{l}\text { Accepted: } \\
\text { 24 September } 2018 \\
\text { Available Online: } \\
\text { 10 October } 2018\end{array}$ \\
\hline
\end{tabular}

\section{Introduction}

Coccidiosis is recognized as one of the major diseases of poultry worldwide. In chicken, at least 7 species of Eimeria genus (Kumar et al.,

\section{A B S T R A C T}

The objective of the present study was to access the field situation with respect to coccidia and coccidiosis in broiler chickens raised in rural Assam through a questionnaire based survey, on farm necropsy and laboratory investigation. Analysis of farm history obtained from 48 small scale broiler farms consisting of 34 integration and 14 non-integration farms managed under deep litter system revealed awareness on coccidia among $27.08 \%$ farmers with occasional occurrence of the disease in their farms. However, examination of faecal and litter samples, intestinal lesions and mucosal scrapings revealed the farm positivity of coccidia to be as high as $83.33 \%$ with $44.44 \%$ of the farms witnessing mortality due to coccidiosis. At birds' level, $62.39 \%$ broilers were found to be coccidia positive and mortality due to coccidiosis was diagnosed in $29.36 \%$ carcasses through lesion study and laboratory investigation. Mortality due to coccidiosis was higher in integration farms (29.17\%) than in nonintegration farms $(12.5 \%)$. The higher the flock size, higher was the chance of occurrence of coccidiosis. The disease was diagnosed throughout the year. However, its record in the wet season $(22.92 \%)$ was found slightly higher than that in the dry season $(18.75 \%)$ of the year. The study indicated high prevalence of coccidia infection in both clinical $(29.36 \%)$ and subclinical farms $(33.03 \%)$ and mortality due to caecal coccidiosis $(62.50 \%)$ was much higher than the intestinal coccidiosis $(37.50 \%)$. Occurrence of the disease at the rate much higher than the farmers' perception level indicated lack of awareness on the disease and poor managemental procedure adopted in the geographical region where the environmental conditions were optimum for the propagation of coccidia parasites. 
caused by the different species may produce haemorrhagic or non-haemorrhagic enteritis leading to a high level of mortality in a flock, the subclinical form is known to be economically more important due to impairment of gut health and feed utilization (Sun et al., 2009; Shirzad et al., 2011). Moreover, the infected birds are predisposed to necrotic and other types of enteritis which have adverse impact on the flock performance and farm profitability (Dahiya et al., 2006; Shawkat et al., 2015). Identification of coccidia and coccidiosis in a farm is important not only for the diagnosis but also to formulate effective management and control measures. Compared to other parts of the country, epidemiology based study and strategy for control of coccidiosis of chicken in the north east region of India has not been undertaken in the recent past. The present study reports the first hand knowledge on the magnitude of coccidia infection in the commercial small scale broiler chicken farms adopted by farmers in rural Assam.

\section{Materials and Methods}

The study was conducted during June, 2015 and May, 2016 in 34 integration and 14 nonintegration commercial broiler chicken farms from three rural districts of Brahmaputra valley of Assam in the north east region of India. The valley usually receives $160-430 \mathrm{~cm}$ (av. $290 \mathrm{~cm}$ ) annual rainfall with humidity ranging between 75 and $85 \%$ and moderate environmental temperature ranging between 6$38^{\circ} \mathrm{C}$. The broiler chicks were raised under deep litter system in batches of 500-1200 birds. In integration type of farms birds, feeds, medicine and technical consultancy were provided by the companies and the infrastructure such as housing, litter materials, farm equipments and appliances, labour cost and management were borne by the marginal farmers. The non-integration farms were run independently by the farmers. The birds of both farm types were maintained with commercial feed available in the market. There was no history of vaccination against coccidiosis in any of the farms.

\section{Farm investigation}

Personal profiles of the farmers with respect to their education, training and experience of poultry farming, perception of coccidia and coccidiosis and other farm related data such as farm type, flock size, birds' age, and mortality pattern were collected through a pre-designed questionnaire. Faecal and litter materials approximately of $100 \mathrm{~g}$ were collected by "W" method (Kumar et al., 2014) in polythene bags from each farm and brought to the laboratory. Carcasses of dead birds and about to die diseased birds showing characteristic symptoms of enteric disorders such as diarrhoea or passing of bloody droppings were presented at farmers' will for post mortem examination in the farm premises. Any abnormalities like ballooning, thickening, haemorrhage, white spots, if present in the different portions of the intestine, were properly recorded.

\section{Laboratory investigation}

Faecal and litter materials were processed by the routine floatation method and examined under microscope for detection of oocysts of coccidia. Individual intestines brought to the laboratory were cut at different portions. The luminal contents and mucosal scrapings were examined microscopically for detection of developmental stages of coccidia and to ascertain the infection.

\section{Data analysis}

Data obtained during field cum laboratory investigation were presented for descriptive analysis by percentage calculation and tabular representation (Table 1). 


\section{Results and Discussion}

Personal interview of the farmers who had school education upto a maximum of class $\mathrm{X}$ standard and were associated with broiler farming without any prior training revealed that $27.08 \%$ of the farmers by experience were aware of coccidia that caused occasional mortality in birds due to excretion of bloody droppings and blood filled caecum distinctly visible at post-mortem. However, on the basis of faecal, litter and post-mortem examination performed in the present study $83.33 \%$ farms were found to be coccidia positive. Coccidiosis death was registered in $44.44 \%$ farms. Lesion study followed by microscopic examination of intestine luminal content and mucosal scrapings done in 109 intestines showed $62.39 \%$ birds as coccidia positive of which coccidiosis was diagnosed in $29.36 \%$ cases. High prevalence of coccidia infection in broilers of Assam is in agreement with the report of Singh and Mohilal (2016) from a neighbouring state in the North East India.

The study indicated a high prevalence of coccidia infection in both clinical $(29.36 \%)$ and subclinical (33.03\%) farms. Further, mortality due to caecal coccidiosis $(62.50 \%)$ was higher than the intestinal type $(37.50 \%)$ as observed by several workers (Sharma et al., 2015). Occurrence of coccidiosis, both clinical and subclinical forms much higher than the farmers' perception level suggest lack of awareness about the disease which is further influenced by poor management in the deep litter system of farming being adopted in this region having high level of rainfall, humidity and ambient environmental temperature as reported by several workers (Jadhav et al., 2012; Jatau et al., 2012; Thenmozi et al., 2013). This also agrees with Bachaya et al., (2012) who reported lower incidence of coccidiosis in the farms run by progressive farmers.

Broiler farms in the study area were mostly integration type which recorded at postmortem higher incidence of coccidiosis $(29.17 \%)$ than that in the non-integration $(12.50 \%)$ farms (Table 1).

Lower incidence of disease in the nonintegration farms might reflect extra managemental care adopted by the farmers for their better economic return. Present finding also revealed higher incidence of coccidiosis in the farms with flock size of more than 1000 birds. This agrees to the reports of Shirzad et al., (2011) terming coccidiosis as a problem under intensive farming system.

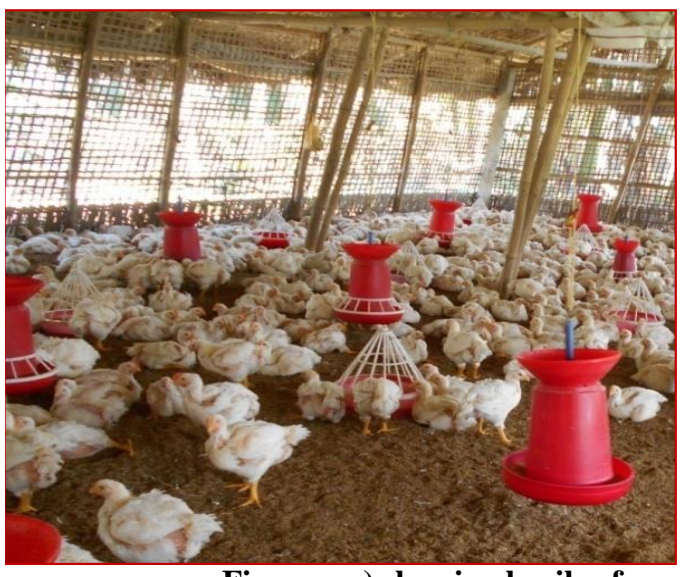

Figures: a) showing broiler farm

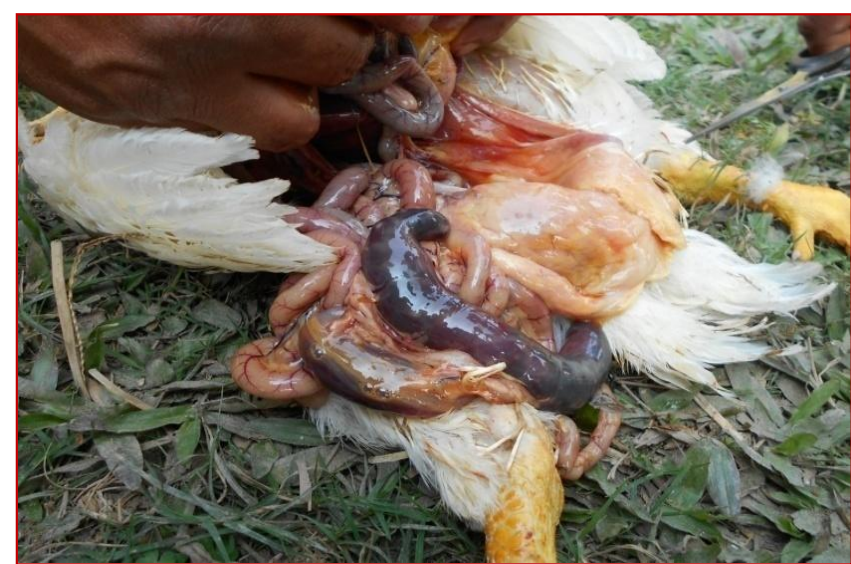

b) Chicken affected with caecal coccidiosis 
Table.1 Relative importance of different risk factors associated with the prevalence of coccidiosis in broiler chicken farms $(\mathrm{N}=48)$

\begin{tabular}{|c|c|c|}
\hline Risk factor & Risk factor Category (Nos.) & No. of farms affected with coccidiosis \\
\hline \multirow[t]{2}{*}{ Farm type } & Integration (34) & $14(29.17)$ \\
\hline & Non- Integration (14) & $6(12.50)$ \\
\hline \multirow[t]{3}{*}{ Flock size } & $100-500$ & $2(4.17)$ \\
\hline & $501-1000$ & $7(14.58)$ \\
\hline & $>1000$ & $11(22.91)$ \\
\hline \multirow[t]{6}{*}{ Age at mortality } & $1^{\text {st }}$ week & $0(\mathbf{0 . 0 0})$ \\
\hline & $2^{\text {nd }}$ week & $4(8.33)$ \\
\hline & $3^{\text {rd }}$ week & $6(12.50)$ \\
\hline & $4^{\text {th }}$ week & $8(16.67)$ \\
\hline & $5^{\text {th }}$ week & $2(4.17)$ \\
\hline & $6^{\text {th }}$ week & $0(\mathbf{0 . 0 0 )}$ \\
\hline \multirow[t]{2}{*}{ Season } & Wet season(Aril-Sept) & $11(22.92)$ \\
\hline & Dry season(Oct-Mar) & $9(18.75)$ \\
\hline
\end{tabular}

However, Al-Natour et al., (2002) recorded no such difference according to flock size. Coccidiosis was witnessed in 2-5 weeks old birds as observed elsewhere (Buragohain and Kalita, 2010). However, Musa et al., (2010) recorded outbreak even in 5 days old broilers. Although the disease was recorded throughout the year, its incidence was slightly higher in the wet season $(22.92 \%$ than the dry season (18.75\%) similar to the reports documented by several workers (Ragmi et al., 2000; Nikam et al., 2012 and Amin et al., 2014). In conclusion, the present study conducted for the first time in broiler chicken farms revealed high prevalence of coccidiosis in both clinical and subclinical forms which remained underestimated due to lack of awareness among the farmers and poor managemental procedure to fight with environment friendly coccidia parasites.

\section{Acknowledgement}

Authors are thankful to the Advanced Animal Disease Diagnosis and Management Consortium, A.A.U, Khanapara for providing facilities.

\section{References}

Al-Natour, M. Q., Suleiman, M. M. and AboShehada, M. N. 2002. Flock level prevalence of Eimeria species among broiler chicks in Northern Jordan. Preventive Veterinary Medicine, 53, 305310.

Amin, Y., Aslem, A., Anwar, K. and Pervez Ali, Z. 2014. Seasonal prevalence of Eimeriosis in broiler chickens. Advances in Life Science, 1,160-164.

Bachaya, H. A., Raza, M. A., Iqbal, Z., Abbas, R. Z., Murtaza, S and Bardar, N. (2012). Predominance and detection of different Eimeria species causing coccidiosis in layer chickens. Journal of Animal and Plant Science, 22, 597-560.

Buragohain, R. and Kalita, G. 2010. Assessment of mortality pattern of broilers under intensive system of management in Mizoram. Tamil Nadu Journal of Veterinary and Animal Science, 6, 339-341.

Dahiya, J. P., Wilkee, D. C., Vankessel, A. G. and Drew, M. D. 2006. Potential strategies for controlling necrotic enteritis 
in broiler chickens in post antibiotic era. Animal Feed Science Technology, 129, 68-88.

Jadhav, B. N., Nikam, S. V. and Bhamare, S. N. 2012. Eimeria infection is a great challenge to poultry industry in Aurangabad district of Maharashtra, India. Elixir Applied Biology, 47, 89738976.

Jatau, I. D., Sulaiman, N. H., Musa, I. W., Lawal, A. I., Okubanjo, O. O., Isah, I. and Magnji, Y. 2012. Prevalence of coccidia infection and prevalence of Eimeria species in free range indigenous and intensively managed exotic chickens during hot-wet season in Zaria, Nigeria. Asian Journal of Poultry Science, 6, 7988.

Kumar, S., Garg, R., Maftah, A., Clark, E. L., Mcdonald, S. E., Chandhry, A. S., Sparagano, O., Banerjee, P. S., Kundu, K., Tomley, F. M. and Blake, D. P. 2014. An optimised protocol for molecular identification of Eimeria from chickens. Veterinary Parasitology, 199, 24-31.

Musa, I. W., Saidu, L., Jatau, I. D., Adamu, J., Otu, M. O. and Abdu, P. A. 2010. Outbreak of coccidiosis in 5 day old commercial broiler breeder flock in Zaria, Nigeria. International Journal of Poultry Science, 9, 1112-1115.

Nikam, S. V., Kansee, V. S., Jadhav, B. N. and Jaid, E. L. 2012. Comparative study of seasonal incidence of chicken coccidiosis in eight districts of Marathwada region, Maharashtra state, Indian Trends in Parasitology Research, 1, 7-9.

Razmi, G. R. and Kalideri, G. A. 2000. Prevalence of subclinical coccidiosis in broiler chicken farms in the municipality of Mushhad, Khorasan, Iran. Preventive Veterinary Medicine, 44, 247-253.

Sharma, S., Iqbal, A., Azmi, S., Mustaq, I., Wani, Z. A. and Ahmed, S. 2015. Prevalence of poultry coccidiosis in Jammu region of Jammu and Kashmir state. Journal of Parasitic Diseases, 39, 85-89.

Shawkat, A., Sadeq, M., Shubia, W., Robert, A.S., and Mingan, C. 2015. Towards the control of necrotic enteritis in broiler chickens with in- feed antibiotics phasing out worldwide. Animal Nutrition, 10, 111.

Shirzad, M. R., Seifi, S., Gheisari, H. R., Hachesoo, B. A., Habibi, H. and Bujmehrani, H. 2011. Prevalence of risk factors for subclinical coccidiosis in broiler chicken farms in Mazandaram Province. Iran. Tropical Animal Health Production, 43, 1601-1604.

Singh, L. J. and Mohilal, N. 2016. Gastrointestinal parasitic infection in diverse species of domestic birds of Manipur, Indian Journal of Parasitic Diseases, 40, 5.

Sun, X. M., Pang, W., Jia, T., Yan, W. C., He, G., Hao, L. L., Bentue, M. and Sue, X 2009. Prevalence of Eimeria species in broilers with subclinical sign from fifty farms. Avian Diseases, 53, 301-305.

Thenmozhi, V., Sairabanu, S., Selvarani, R., Raman, M., Gomathinayagam, S. and Dhinakar Raj, G. 2013. Prevalence of Avian Eimeria species in commercial poultry in Southern India. Indian Veterinary Journal, 90, 24-25.

\section{How to cite this article:}

Kalita, A., P.C. Sarmah, M.K. Borah, L. Hussain and Bhattacharjee, K. 2018. Magnitude of Coccidia Infection in Small Scale Broiler Chicken Farms of Rural Assam (India). Int.J.Curr.Microbiol.App.Sci. 7(10): 3399-3403. doi: https://doi.org/10.20546/ijcmas.2018.710.394 